\title{
Glucocorticoid therapy increases COX-2 gene expression in nasal polyps in vivo
}

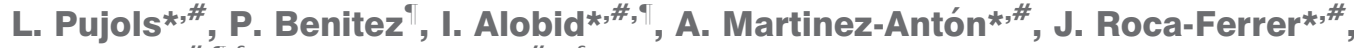 \\ J. Mullol ${ }^{\star, \#, \uparrow, \S}$ and C. Picado*,\#,,§
}

ABSTRACT: The aim of the present study was to evaluate the in vivo regulation of cyclooxygenase-2 in nasal polyps.

In total, 65 patients with nasal polyps were randomly (3:1) treated with $(n=51 ; 33$ with asthma) or without $(n=14)$ oral prednisone and intranasal budesonide for 2 weeks plus intranasal budesonide for 10 additional weeks. Biopsies were obtained at baseline and after 2 and 12 weeks of treatment. All samples were analysed for cyclooxygenase-1 and cyclooxygenase-2 mRNA. Attempts were made to detect cyclooxygenase-2 protein.

At baseline, cyclooxygenase-1 and cyclooxygenase-2 expression did not differ between polyps from nonasthmatic and asthmatic patients. Cyclooxygenase-1 mRNA was unchanged by glucocorticoid treatment, while cyclooxygenase-2 mRNA increased in glucocorticoid-treated patients at week 2 compared with baseline and then decreased at week 12. Within subgroups, increased cyclooxygenase-2 mRNA was found at week 2 in polyps from nonasthmatic and asthmatic patients compared with baseline. At week 12, cyclooxygenase-2 expression remained high in nonasthmatics while it decreased in asthmatics. Cyclooxygenase-2 protein was not detected under any circumstances.

Glucocorticoid therapy enhances cyclooxygenase-2 expression in vivo in nasal polyps, a finding that does not follow the generally accepted assumption that cyclooxygenase-2 expression is suppressed by glucocorticoids.

KEYWORDS: Cyclooxygenase-1, cyclooxygenase-2, glucocorticoids, nasal polyps

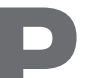

rostaglandin (PG) endoperoxidase synthase, known as cyclooxygenase $(\mathrm{COX})$ is the rate-limiting enzyme in the biosynthesis of PG. There are two distinct enzymes, COX-1 and COX-2. While COX-1 is constitutively expressed in most cells, the expression of COX-2 is generally low under basal conditions but is usually induced by inflammatory mediators, mitogens and growth factors. Many observations indicate that the expression of COX-2 plays key roles in inflammation and tumorigenesis [1].

Over-expressed COX-2, in response to stressful signals, has been shown to be a major source of PG. PG can exert opposing effects on inflammatory response in the airways. Mast cells release $\mathrm{PGD}_{2}$, which is partly responsible for the bronchoconstriction that usually occurs in immediate allergic responses. In contrast, $\mathrm{PGE}_{2}$ can exert both beneficial and adverse effects. Inhalation of a high $\mathrm{PGE}_{2}$ dose causes bronchoconstriction while a low dose prevents exercise-induced bronchoconstriction, early- and late-phase allergic airway reactions, and aspirin-induced broncoconstriction [2-4]. Together, the experimental data and clinical findings indicate that COX-2 induction may be a friend or a foe in the lung $[5,6]$.

Despite the fact that the COX-2 enzyme is induced in states of inflammation, this is not the case in the nasal polyps of asthmatic patients, which show no increase in the expression of the enzyme $[7,8]$. This lack of upregulation of COX-2 in the inflamed tissue of nasal polyps is more marked in asthma patients with aspirin intolerance, where the level of COX-2 expression is even lower than in aspirin-tolerant asthmatics [8-10]. The mechanisms responsible for this abnormal response are, as yet, unclear. Whether downregulation of COX-2 is involved in the formation of nasal polyps or is a collateral consequence of the nasal inflammatory process remains to be elucidated.
AFFILIATIONS

*Institut d'Investigacions

Biomèdiques August Pi i Sunyer (IDIBAPS),

\# Centro de Investigaciones Biomédicas en Red (CIBER) Enfermedades Respiratorias,

'Servei d'Otorrinolaringologia,

+'Servei de Pneumologia i Allèrgia Respiratoria, Hospital Clínic, Universitat de Barcelona, Barcelona, Spain.

${ }^{\S}$ Both authors contributed equally to this work with senior responsibilities.

CORRESPONDENCE

C. Picado

Servei de Pneumologia

Hospital Clínic. Villarroel 170

08036 Barcelona

Spain

Fax: 34934515272

E-mail: cpicado@ub.edu

Received:

February 052008

Accepted after revision:

October 272008

SUPPORT STATEMENT

The present study was supported by Fondo de Investigaciones Sanitarias (PI 050108) and Sociedad Española de Neumologia y Cirugia Torácica (SEPAR)

\section{STATEMENT OF INTEREST}

Statements of interest for J. Mullol and $\mathrm{C}$. Picado can be found at www.erj.ersjournals.com/misc/ statements.shtml 
TABLE 1 Demographic data and clinical characteristics of the study population

\begin{tabular}{|c|c|c|c|c|}
\hline & \multirow[t]{2}{*}{ Nontreated group } & \multicolumn{3}{|c|}{ GC-treated group } \\
\hline & & Without asthma & \multicolumn{2}{|c|}{ With asthma } \\
\hline Patients $\mathbf{n}$ & 14 & 18 & 16 & 17 \\
\hline Skin prick test \% positivity & 28.6 & 27.8 & 25.0 & 29.4 \\
\hline
\end{tabular}

Data are presented as mean \pm SEM unless stated otherwise. GC: glucocorticoid; ATA: aspirin-tolerant asthma; AIA: aspirin-intolerant asthma.

Glucocorticoids (GCs) represent the most effective treatment for several clinical conditions and are used for their anti-inflammatory effects in the treatment of nasal polyps [11]. GCs have been shown to modulate the expression of several genes involved in inflammatory responses. One of the target genes for GC action appears to be the COX-2 gene, suppressed through both transcriptional and post-transcriptional mechanisms [12-14].

However, the ability of GC to decrease COX-2 expression in the airways is not entirely clear. At least one group has found that GC can decrease COX-2 expression in the bronchial mucosa of asthma patients [15] but others have reported no change in its expression in either bronchial mucosa of patients with asthma [16] or nasal polyps after GC therapy [10]. Similarly, in vitro studies also show disparate results, with some reports showing a decrease [12-14] and others an increase [17] in the expression of COX-2 after the exposure of various cells and tissues to GC.

It is difficult to determine the true effect of GC on COX-2 in airways, as the in vivo studies are comparison studies of different groups of patients in cross-sectional studies [10, 15, 16 ] and the in vitro studies vary widely with regard to the type of cells, the methodology used and the duration of exposure to treatment [10, 12-14].

The only way to clarify whether GC increase or decrease COX-2 expression in vivo is through a prospective study comparing the level of expression of the enzyme in tissues obtained from the same subjects before and after GC therapy. With this objective in mind, serial nasal polyp biopsies were performed on patients treated with GC and the local COX-2 mRNA and protein expression was evaluated.

\section{SUBJECTS AND METHODS \\ Study subjects}

A total of 65 patients ( $74 \%$ male, age $51 \pm 2$ yrs) with diagnosis of severe nasal polyposis were selected, comprising patients without asthma and patients with either aspirin-tolerant or aspirin-intolerant asthma (ATA and AIA, respectively). Severe nasal polyposis, atopy, asthma and aspirin sensitivity were diagnosed as described elsewhere $[18,19]$ (see supplementary material). All subjects agreed to participate in the study, which was approved by the Ethics Committee of the Hospital Clinic from Barcelona (Spain). Table 1 summarises the subjects' demographic data and clinical characteristics.

\section{Study design}

The study design used herein has been previously reported [18]. After a 4-week washout period with no intranasal or oral steroids, patients were randomised (3:1) into two groups. 1) The GC-treated group included 51 patients who received oral prednisone (30 $\mathrm{mg}$ daily for 4 days followed by a tapering of $5 \mathrm{mg}$ every 2 days) and intranasal budesonide $(400 \mu \mathrm{g}$ b.i.d.) for 2 weeks (w2), followed by intranasal budesonide (400 $\mu \mathrm{g}$

TABLE 2 Inflammatory cell counts of nasal polyp biopsies from nontreated or glucocorticoid (GC)-treated patients

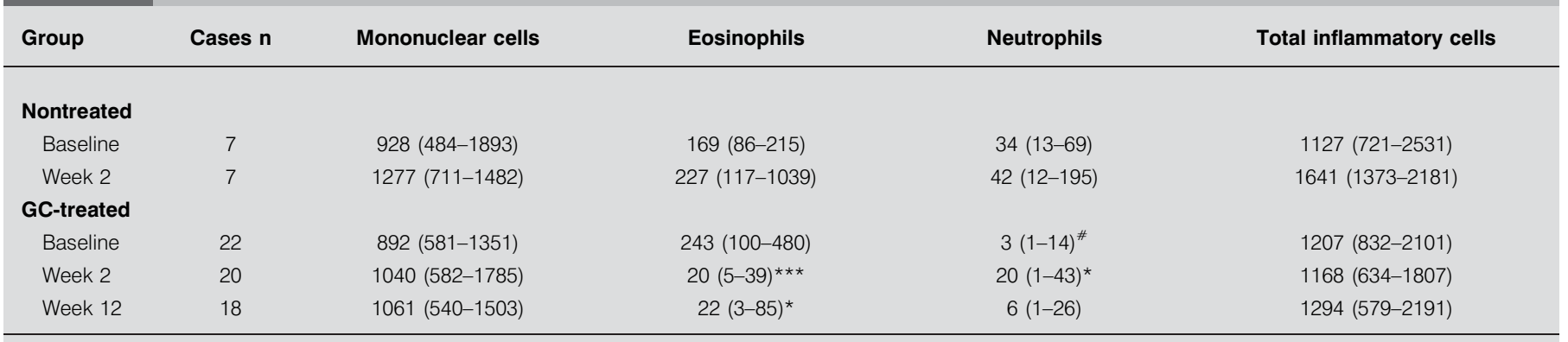

Data are presented as median (interquartile range) cells $\cdot \mathrm{mm}^{-2}$, unless otherwise stated. Total inflammatory cells correspond to the sum of mononuclear cells, eosinophils, and neutrophils. ${ }^{*}: \mathrm{p}<0.05 ;{ }^{* *}: \mathrm{p}<0.001$; both compared with baseline from GC-treated group (Wilcoxon test). ${ }^{*}: \mathrm{p}<0.01$ compared with baseline from the nontreated group (Mann-Whitney U-test) 


\begin{tabular}{|c|c|c|c|}
\hline \multirow[t]{2}{*}{ TABLE 3} & \multicolumn{3}{|c|}{$\begin{array}{l}\text { Basal expression of cyclooxygenase (COX)- } 1 \\
\text { and COX-2 mRNAs in the different subtypes of } \\
\text { nasal polyps (all patients) }\end{array}$} \\
\hline & Cases n & cox-1 & cox-2 \\
\hline Without asthma & 24 & $3.29(0.96-5.93)$ & $0.21(0.05-0.47)$ \\
\hline With asthma & 41 & $3.96(2.02-6.66)$ & $0.23(0.06-0.37)$ \\
\hline ATA & 21 & $4.81(2.32-7.18)$ & $0.24(0.08-0.35)$ \\
\hline AIA & 20 & $2.98(1.65-6.01)$ & $0.20(0.05-0.61)$ \\
\hline \multicolumn{4}{|c|}{$\begin{array}{l}\text { Data are presented as median (interquartile range) } \times 10^{6} \mathrm{cDNA} \text { copies } \mu \mathrm{g}^{-1} \\
\text { total RNA, unless otherwise stated. ATA: aspirin-tolerant asthma; AIA: aspirin- } \\
\text { intolerant asthma. No significant differences in either COX-1 or COX- } 2 \text { mRNA } \\
\text { expression among the different nasal polyp subtypes were found (Mann- } \\
\text { Whitney U-test and Kruskal-Wallis). }\end{array}$} \\
\hline
\end{tabular}

b.i.d.) alone for 10 additional weeks (w12). 2) The nontreated group included 14 patients who did not receive any steroid treatment over a 2-week period (w2). For ethical reasons, patients from the nontreated group were not kept for more than 6 weeks without any effective treatment. Nasal polyp biopsies were obtained from all patients at baseline, w2 (treated and nontreated groups) and w12 (treated group).

\section{Histological analysis}

The inflammatory content of biopsies, i.e. mononuclear cells, neutrophils, and eosinophils, was characterised by haematoxylin and eosin staining in $4-\mu \mathrm{m}$ thick paraffin sections. Sections were counted blindly using an Olympus microscope $(\times 400$ magnification). Between 1.6 and $2 \mathrm{~mm}^{2}$ were counted for each section and cell counts were expressed as the number of positive cells $\cdot \mathrm{mm}^{-2}$. Due to limitations in the amount of tissue obtained at three points (baseline, w2 and w12) and the preferential use of tissues for RT-PCR and protein analysis, the histological analysis could be completed in only 29 patients.

\section{Reverse transcription and real-time PCR}

The extraction of total RNA from the specimens and the reverse transcription step were performed as previously reported $[9,10]$. Quantification of COX-1 and COX-2 transcripts was achieved by extrapolation to a plasmid doublestranded DNA external standard curve added in each PCR run. The detailed protocol and validation of the real-time PCR assays have been reported elsewhere (see supplementary material) [9].

\section{Western blot and ELISA of COX-2}

Total proteins from the nasal polyp biopsies were extracted as described elsewhere [20] and analysed for the expression of COX-2 protein through both Western blot [20] and ELISA using the ZYMED COX-2 ELISA kit (ZYMED laboratories INC, San Francisco, CA, USA). The detection range of the ELISA kit was from 2.15 to $275 \mathrm{ng} \cdot \mathrm{mL}^{-1}$ (see supplementary material).

\section{Statistical analysis}

Data are expressed as median and interquartile range. Nonparametric statistical analysis was performed by using the Friedman test and Wilcoxon rank test for within-group comparisons, and the Kruskal-Wallis test and Mann-Whitney U-test for between-group comparisons. Spearman rank correlation was used when analysing relationships between data. A p-value of $<0.05$ was considered to be significant.

The sample size of the study was established from practical considerations. The estimated statistical power for the present sample size (51 GC-treated patients) to detect a two-fold change in the median of the main variable (COX-2 mRNA) was $82 \%$ when analysed with a nonparametric approach (Wilcoxon test), with an $\alpha$ error of $5 \%$ two-sided.

\section{RESULTS}

\section{Subjects}

As expected, GC therapy significantly improved clinical symptoms, reduced nasal polyp size and relieved nasal obstruction. A detailed description of the clinical results has been previously reported elsewhere [18].

\section{Histological findings}

Except for neutrophils, at baseline, there were no significant differences in the number of inflammatory cells between GCtreated and nontreated control groups (table 2).

There were no significant changes in the inflammatory cell counts between baseline and $\mathrm{w} 2$ in the nontreated group (table 2). In contrast, at w2, GC-treated patients showed a marked downregulation in the number of eosinophils, which remained low at $\mathrm{w} 12$ and an increase in the number of neutrophils compared with baseline (table 2). The reduction in eosinophils at w2 was found in both nonasthmatic (median 20 (interquartile range $15-38) ; \mathrm{n}=8 ; \mathrm{p}<0.05)$ and asthmatic patients (18 (3-55); $\mathrm{n}=12 ; \mathrm{p}<0.01)$, compared with baseline (no asthma: 199 (96-339); $\mathrm{n}=9$; asthma: 285 (126-808); $\mathrm{n}=13$ ). However, the reduction in eosinophils at w12 was more pronounced in the nonasthmatics $(13$ (3-71); $\mathrm{n}=8 ; \mathrm{p}<0.05$ compared with baseline) than in the asthmatic patients (41 (3283); $\mathrm{n}=10$; nonsignificant compared with baseline). No differences in the response to GC treatment were apparently found between ATA and AIA patients. However, given the low number of patients available for histological analysis, caution has to be taken when comparing subgroup differences.

The increase in neutrophil numbers at w2 in all patients (table 2) did not reach statistical significance when they were subdivided in nonasthmatics (w2: 17 (1-47) versus w0: 2 (1-13); $\mathrm{p}=0.07)$ and asthmatics (w2: $20(1-40)$ versus w0: 4 (2-30); $\mathrm{p}=0.07)$, nor in ATA and AIA patients.

\section{Basal expression of COX-1 and COX-2 mRNA}

When all patients were analysed at baseline, no significant differences in COX-1 or COX-2 mRNA expression were found in nasal polyps between nonasthmatic and either ATA or AIA patients (table 3).

\section{COX-1 and COX-2 mRNA expression after treatment with GCs}

At baseline, there were no significant differences in COX-1 mRNA expression between treated and nontreated groups (fig. 1a). There were no significant changes in COX-1 mRNA levels between baseline and w2 in the nontreated group, nor between baseline and either w2 or w12 in the treated group (fig. 1a). Within the treated patients, no significant changes in 

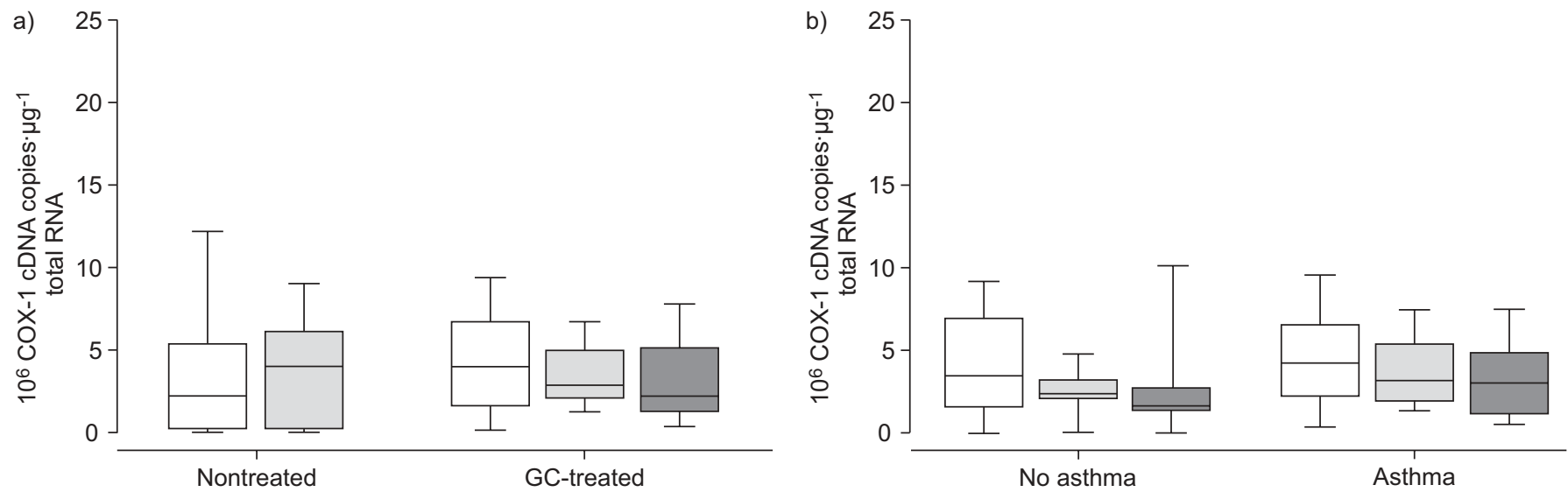

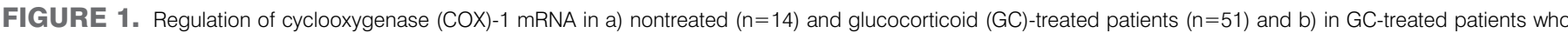

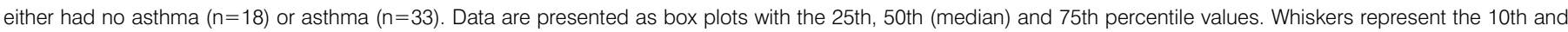

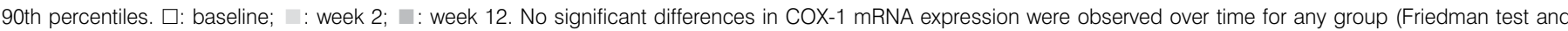
Wilcoxon test).

COX-1 expression were found at $\mathrm{w} 2$ and $\mathrm{w} 12$ compared to baseline in nasal polyps from both nonasthmatic and asthmatic patients (fig. 1b).

There were no significant changes in COX-2 mRNA expression between baseline and $\mathrm{w} 2$ in the nontreated group, while COX-2 mRNA was seen to be increased in treated patients at w2 compared with baseline. COX-2 mRNA expression decreased significantly at w12, compared with w2 (fig. 2a and table 4). Interestingly, a different response to GC treatment was found between nonasthmatic and asthmatic patients (fig. $2 \mathrm{~b}$ and table 4). Thus, in nonasthmatic patients, increased COX-2 expression was found at w2 and w12 compared with baseline. However, in asthmatic patients, COX-2 expression increased at w2, compared with baseline, and decreased to basal levels at w12. The same apparent pattern of regulation, i.e. increase in COX-2 mRNA levels at $\mathrm{w} 2$ and return to basal

\begin{tabular}{ccccc} 
TABLE 4 & $\begin{array}{l}\text { Effect of glucocorticoid (GC) treatment on } \\
\text { cyclooxygenase-2 mRNA in the different } \\
\text { subtypes of nasal polyps }\end{array}$ \\
\hline $\begin{array}{c}\text { Group } \\
\text { Cases } \\
\mathbf{n}\end{array}$ & Baseline & Week 2 & Week 12 \\
\hline $\begin{array}{c}\text { Nontreated } \\
\text { GC-treated } \\
\text { Without } \\
\text { asthma }\end{array}$ & 14 & $0.19(0.02-0.48)$ & $0.21(0.08-0.55)$ & \\
With & 18 & $0.23(0.13-0.44)$ & $0.37(0.08-1.12)^{*}$ & $0.39(0.21-0.65)^{*}$ \\
asthma & 33 & $0.23(0.07-0.37)$ & $0.47(0.21-0.86)^{*}$ & $0.26(0.07-0.51)^{\# \#}$ \\
ATA & 16 & $0.24(0.11-0.34)$ & $0.55(0.21-0.92)$ & $0.19(0.07-0.51)$ \\
AlA & 17 & $0.18(0.05-0.60)$ & $0.40(0.21-0.69)$ & $0.27(0.04-0.52)$ \\
\hline
\end{tabular}

Data are presented as median (interquartile range) $\times 10^{6} \mathrm{cDNA}$ copies $\cdot \mathrm{\mu g}^{-1}$ total RNA, unless otherwise stated. ATA: aspirin-tolerant asthma; AIA: aspirinintolerant asthma. ${ }^{*}: p<0.05 ; * *: p<0.01$; both compared with baseline (Wilcoxon test). ${ }^{\#}: \mathrm{p}<0.05 ;{ }^{\# \#}: \mathrm{p}<0.01$; both compared with week 2 (Wilcoxon test) levels at w12, was observed in both ATA and AIA patients, although changes did not achieve statistical significance (table 4).

A weak but statistically significant negative correlation was found between COX-2 mRNA levels and eosinophil counts $(\mathrm{r}=-0.307 ; \mathrm{n}=73 ; \mathrm{p}<0.01)$. However, changes in COX-2 mRNA levels did not correlate with changes in eosinophil numbers after GC treatment. Changes in COX-2 mRNA also did not correlate with the increase in neutrophil numbers at w2.

\section{COX-2 protein expression}

COX-2 protein was not detected through ELISA in any tissue or at any time-point. Western blot analysis revealed absence of COX-2 protein at baseline and occasional faint bands corresponding to COX-2 protein after GC treatment in a few tissues, which were difficult to quantify (fig. 3).

\section{DISCUSSION}

It is generally accepted that COX-2 is upregulated under conditions of inflammation and that the COX-2 derived eicosanoids are mostly pro-inflammatory. Because eicosanoids are generally considered to be potent pro-inflammatory mediators, their inhibition by GC and nonsteroidal anti-inflammatory drugs (NSAIDs) has been considered a desirable therapeutic goal. However, many recent observations question these assumptions, particularly when they are applied to asthma and idiopathic interstitial lung fibrosis $[5,6,21]$.

In asthma and nasal polyps, and most obviously in those patients with aspirin-sensitivity, there are intriguing data to support the existence of a substantial disregulation of the COX-2 pathway. COX-2 and/or $\mathrm{PGE}_{2}$ levels have been reported to be downregulated in nasal polyps [7-10, 22] as well as in bronchial fibroblasts [23] and bronchial smooth muscle [24] from asthmatic patients. No significant differences in the expression of COX-2 were found between ATA and AIA subjects, which concurs with previous reports showing that kinetic studies are sometimes necessary to demonstrate differences in the expression of COX-2 between ATA and AIA asthma patients [9], and between healthy nasal mucosa 

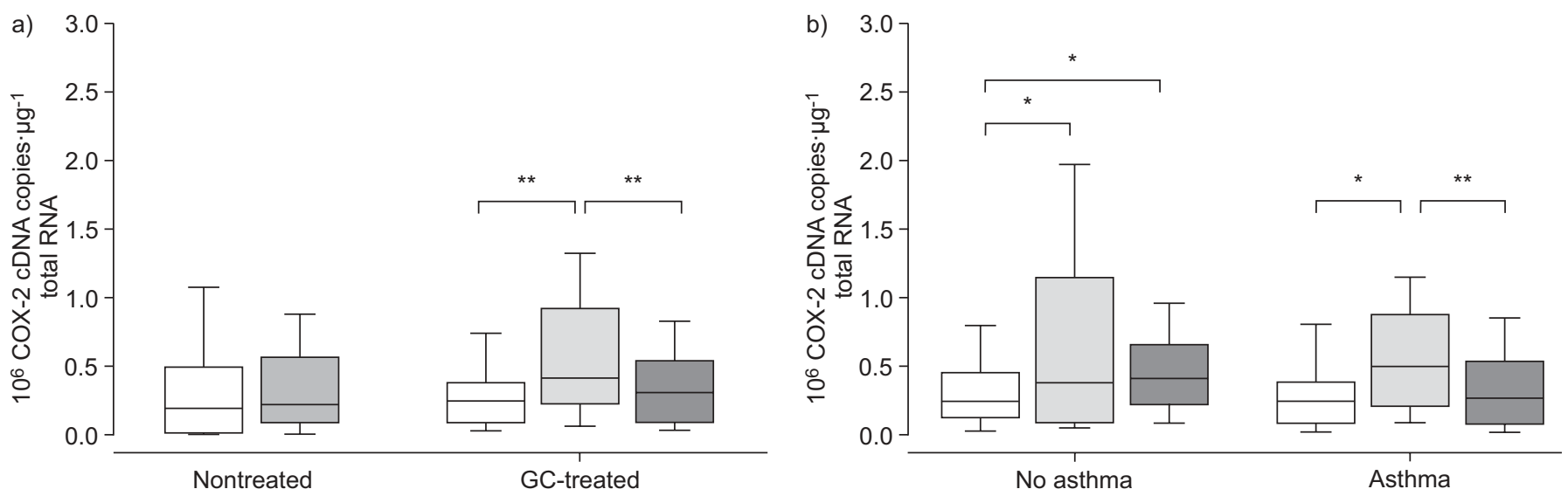

FIGURE 2. Regulation of cyclooxygenase (COX)-2 mRNA in a) nontreated ( $n=14)$ and glucocorticoid (GC)-treated patients ( $n=51)$ and $b)$ in $G C$-treated patients who either had no asthma $(n=18)$ or asthma $(n=33)$. Data are presented as box plots with the 25th, 50th (median) and 75 th percentile values. Whiskers represent the 10th and

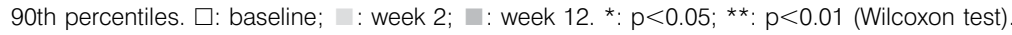

and nasal polyps [7]. $\mathrm{PGE}_{2}$ appears to be a modulator of the airway inflammatory response rather than to act as a proinflammatory substance [2-6]. Inhibition of the COX pathway by NSAIDs in asthmatic patients generally has no beneficial effect. Indeed, NSAIDs can precipitate severe asthma reactions in some patients, which can be prevented by pre-treatment with $\mathrm{PGE}_{2}$ [3].

In contrast to what was expected, the present study shows that GC increased COX-2 mRNA in nasal polyps, a new intriguing finding to add to the altered regulation of COX-2 in this inflamed nasal tissue. The initial intense therapy with systemic and intranasal GC caused a significant increase of COX-2 mRNA in both nonasthmatic and asthmatic patients causing, in the latter, a return to baseline expression levels after prednisone withdrawal and treatment with intranasal GC alone for 10 additional weeks. In parallel, the 2-week oral and intranasal GC treatment provoked a marked reduction in eosinophil numbers and an increase in neutrophils. These differential effects of GC on inflammatory cells have been previously reported and ascribed to the opposing effects of GC on the regulation of apoptosis in eosinophils (increased apoptosis) and neutrophils (decreased apoptosis) [25]. When patients were treated with the less-potent intranasal GC

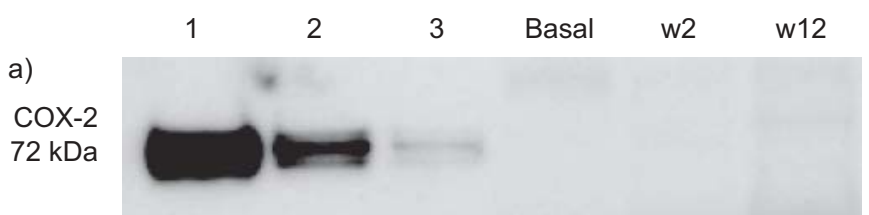

b)

$\beta$-actin

$42 \mathrm{kDa}$

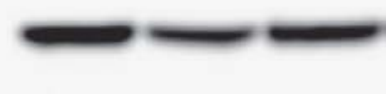

FIGURE 3. a) Representative image of cyclooxygenase (COX)-2 protein in a nasal polyp detected through Western blot at baseline (basal) and after 2 (w2) and 12 weeks (w12) of glucocorticoid (GC) treatment. 1, 2 and 3 denote serial dilutions of the COX-2 standard (11, 5.5 and $2.75 \mathrm{ng}$, respectively). Note the absence of COX-2 at baseline, w2 and w12. b) Western blot for $\beta$-actin, demonstrating a similar protein load in all lanes. therapy, eosinophil numbers increased in nasal polyps of patients with asthma compared with oral GCs, while in nonasthmatic patients the eosinophilic infiltrate remained low. These findings suggest that the presence of a greater inflammatory activity in the nasal polyps of patients with asthma resulted in an earlier relapse of the eosinophilic infiltrate after prednisone withdrawal. Interestingly enough, COX-2 mRNA expression appears to run in parallel with changes in the inflammatory cell infiltrate. Accordingly, a weak but significant negative correlation was found between COX-2 mRNA levels and eosinophil counts, though changes in COX-2 mRNA did not correlate with changes in eosinophils after GC treatment. Thus, changes in COX-2 mRNA induced by GC treatment may involve a direct effect of GC on the regulation of the COX-2 gene, but may also, at least in part, be a consequence of changes in the tissue cell composition.

COX-2 protein was not detected either at baseline or post-GC treatment. This is not an unexpected result because COX-2 protein is not usually found by Western blot at baseline in either nasal mucosa or bilateral nasal polyps [7, 14]. Potent inflammatory stimuli are usually needed to induce the production of detectable levels of COX-2 protein in in vitro studies [7]. COX-2 protein can also be found in vivo in diseases with demonstrated high production of PGs such as cystic fibrosis [20]. Since COX-2 protein was not detected under any circumstances, it is unknown whether the mild GC-induced increase in COX-2 mRNA found in the present study results in an increased translation to COX-2 protein. It is also unknown if GC treatment in the present study has any effect on prostaglandin production.

It is unclear whether the GC effect on COX-2 mRNA expression occurs in inflamed nasal tissue only or whether it can also take place in healthy nasal mucosa. For ethical reasons, nasal biopsies from healthy subjects before and after GC therapy could not be obtained.

Interestingly enough, the present observation concurs with another previously reported by DWORSKI et al. [26], who unexpectedly also found that COX-2 mRNA expression significantly increased in alveolar macrophages and blood monocytes from atopic asthma patients treated with $30 \mathrm{mg}$ of 
prednisone for 7 days, while the same treatment resulted in a decreased expression of COX-2 mRNA in the same cells from healthy subjects. In contrast with the results obtained in vivo, the expression of COX-2 mRNA was significantly inhibited when stimulated monocytes from atopic asthmatic patients and healthy subjects were exposed to dexamethasone ex vivo [26].

Thus, in spite of the fact that in this study the GC-induced increase of COX-2 mRNA might be partly ascribed to the effects of GC on the inflammatory infiltrate, the present results, together with those reported by DWORSKI et al. [26], support the hypothesis that GC therapy upregulates COX-2 expression in vivo in cells and airway tissues of patients with asthma and nasal polyps.

The present authors cannot find an explanation for the increased expression of COX-2 with GC therapy in asthma/ nasal polyps. Based on the dichotomy in the effect of GC in vivo with respect to the ex vivo situation found by DWORSKI et al. [26], the present authors hypothesise that components of the inflammatory process that underlie asthma and nasal polyps might be responsible for the restricted expression of the COX-2 gene. GC therapy might reduce the activity of one or more of these components, which would allow a partial release of the restrained COX-2 gene expression.

In summary, the present study provides evidence that glucocorticoid therapy can enhance the expression of cyclooxygenase-2 mRNA in nasal polyps. These results, together with previous observations, support the notion that the regulation of cyclooxygenase-2 in nasal polyps does not follow either the generally accepted notion that this enzyme is upregulated under conditions of inflammation, or the assumption that cyclooxygenase- 2 expression is suppressed by glucocorticoids. Identification of the mechanisms involved in these distinct responses may help to better understand the role of prostanoids in the regulation of inflammation in airway diseases.

\section{ACKNOWLEDGEMENTS}

The authors would like to thank F. Torres (Universitat Autònoma de Barcelona - Clinical Pharmacology Service, IDIBAPS, Hospital Clínic, Barcelona, Spain), who provided assistance in the statistical analysis.

\section{REFERENCES}

1 Smith WL, DeWitt DL, Garavito RM. Cyclooxygenases: structural, cellular, and molecular biology. Ann Rev Biochem 2000; 69: 145-182.

2 Gauvreau GM, Watson RM, O'Byrne PM. Protective effects of inhaled $\mathrm{PGE}_{2}$ on allergen-induced airway response and airway inflammation. Am J Respir Crit Care Med 1999; 159: 31-36.

3 Sestini P, Armetti L, Gambaro G, et al. Inhaled PGE prevents aspirin-induced bronchoconstriction and urinary LTE4 excretion in aspirin-sensitive asthma. Am J Respir Crit Care Med 1996; 153: 572-575.

4 Melillo E, Woolley KL, Manning PJ, Watson RM, O'Byrne PM. Effects of inhaled $\mathrm{PGE}_{2}$ on exercise-induced bronchoconstriction in asthmatics subjects. Am J Respir Crit Care Med 1994; 149: 1138-1141.
5 Vancheri C, Mastruzzo C, Dortino MA, Crimi N. The lung as a privileged site for the beneficial actions of $\mathrm{PGE}_{2}$. Trends Immunol 2004; 1: 40-46.

6 Yedgar S, Krimsky M, Cohen Y, Flower RJ. Treatment of inflammatory diseases by selective eicosanoid inhibition: a double-edged sword? Trends Pharmacol Sci 2007; 28: 459-464.

7 Mullol J, Fernàndez-Morata JC, Roca-Ferrer J, et al. Cyclooxygenase 1 and cyclooxygenase 2 expression is abnormally regulated in human nasal polyps. J Allergy Clin Immunol 2002; 109: 824-830.

8 Pérez-Novo CA, Watelet JB, Claeys C, Van Cauwenberge P, Bachert C. Prostaglandins, leukotriene, and lipoxin balance in chronic rhinosinusitis with and without nasal polyposis. J Allergy Clin Immunol 2005; 115: 1189-1196.

9 Pujols L, Mullol J, Alobid I, Roca-Ferrer J, Xaubet A, Picado C. Dynamics of COX-2 in nasal mucosa and nasal polyps from aspirin-tolerant and aspirin-intolerant patients with asthma. J Allergy Clin Immunol 2004; 114 814-819.

10 Picado C, Fernandez-Morata JC, Juan M, et al. Cyclooxygenase-2 mRNA is downexpressed in nasal polyps from aspirin-sensitive asthmatics. Am Rev Respir Crit Care Med 1999; 160: 291-296.

11 Fokkens W, Lund V, Mullol J; European Position Paper on Rhinosinusitis and Nasal Polyps group. European position paper on rhinosinusitis and nasal polyps 2007. Rhinol Suppl 2007; 20: 1-136.

12 Nishimori $\mathrm{T}$, Inou $\mathrm{H}$, Hirata $\mathrm{Y}$. Involvement of the 3'unstranslated region of cyclooxygenase- 2 gene in its posttranscriptional regulation through the glucocorticoid receptor. Life Sciences 2004; 74: 2505-2513.

13 Lasa M, Brook M, Saklatvala J, Clark AR. Dexamethasone desestabilizes cyclooxygenase 2 mRNA by inhibiting mitogen-activated protein kinase p38. Mol Cell Biol 2001; 21: 771-780.

14 Fernández-Morata JC, Mullol J, Fuentes $\mathrm{M}$, et al. Regulation of cyclooxygenase- 1 and -2 in human nasal mucosa. Effects of cytokines and dexamethasone. Clin Exp Allergy 2000; 30: 1275-1284.

15 Redington AE, Meng QH, Springall DR, et al. Increased expression of inducible nitric oxide synthase and cyclooxygenase- 2 in the airway epithelium of asthmatic subjects and regulation by corticosteroid treatment. Thorax 2001; 56: 351-357.

16 Taha R, Olivenstein R, Utsumi $\mathrm{T}$, et al. Prostaglandin $\mathrm{H}$ synthase 2 expression in airway cells from patients with asthma and chronic obstructive pulmonary disease. Am J Respir Crit Care Med 2000; 161: 636-640.

17 Zakar T, Hirst JJ, Mijovic JE, Olson DM. Glucocorticoids stimulate the expression of prostaglandin endoperoxide $\mathrm{H}$ synthase-2 in amnion cells. Endocrinology 1995; 136: 16101619.

18 Benítez P, Alobid I, de Haro J, et al. A short course of oral prednisone followed by intranasal budesonide is an effective treatment of severe nasal polyps. Laryngoscope 2006; 116: 770-775.

19 Casadevall J, Ventura PJ, Mullol J, Picado C. Intranasal challenge with aspirin in the diagnosis of aspirin intolerant asthma: evaluation of nasal response by acoustic rhinometry. Thorax 2000; 55: 921-924. 
20 Roca-Ferrer J, Pujols L, Gartner S, et al. Upregulation of COX-1 and COX-2 in nasal polyps in cystic fibrosis. Thorax 2006; 61: 592-596.

21 Gilroy DW, Colville-Nash PR, Willis D, Chivers J, PaulClark MJ, Willoughby DA. Inducible cyclooxygenase may have anti-inflammatory properties. Nat Med 1999; 5: 698-701.

22 Kowalski ML, Pawliczak R, Wozniak J, et al. Differential metabolism of arachidonic acid in nasal polyp epithelial cells cultured from aspirin-sensitive and aspirin-tolerant patients. Am J Respir Crit Care Med 2000; 161: 391-398.

23 Pierzchalska M, Szabó Z, Sanak M, Soja J, Szczeklik A. Deficient prostaglandin $\mathrm{E}_{2}$ production by bronchial fibroblasts of asthmatic patients, with special reference to aspirin-induced asthma. J Allergy Clin Immunol 2003; 111: 1041-1048.

24 Chambers LS, Black JL, Ge Q, et al. PAR-2 activation, $\mathrm{PGE}_{2}$, and COX-2 in human asthmatic and nonasthmatic airway smooth muscle cells. Am J Physiol Lung Cell Mol Physiol 2003; 285: L619-L627.

25 Sivertson KL, Seeds MC, Long DL, Peachman KK, Bass DA. The differential effect of dexamethasone on granulocyte apoptosis involves stabilization of Mcl-1L in neutrophils but not in eosinophils. Cell Immunol 2007; 246: 34-45.

26 Dworski RT, Funk CD, Oates JA, Sheller JR. Prednisone increases PGH-synthase 2 in atopic humans in vivo. Am J Respir Crit Care Med 1977; 155: 351-357. 